\title{
Why to publish a special issue for young researchers?
}

This special issue is dedicated to young researchers/ professors developing their activities in chemistry, either in Brazilian Universities or Research Institutes. The idea was born among the editors of the JBCS as a way to publicize research activities run by young researchers that had been incorporated into the national research system in the last 10 years.

It is well known that achieving a position as professor in a university or researcher in a research institute is a difficult task and involves many years in the postdoctoral regime, from which it is not a simple duty to move to an academic position. The reasons for this paradigm are many and complex, but everything is reflected in an increase in competitiveness to incorporate into academic life. This fact is undoubtedly related to the increase of very well trained $\mathrm{PhDs}$ available in the market and also to the fact that researchers have migratory habits, which globalizes the competition. A career to achieve an academic position leads to many hours of work, job insecurity during $\mathrm{PhD}$ and postdoctoral time, relatively low salary expectations, lots of pressure and competition, lack of opportunities and fear of failure. All this makes the early years of the career difficult, as in other jobs, but the difficulties of planning a career in science may lead young scientists to become disheartened. However, this effort is part of the beginning of an academic career that can be both successful and stimulating.

Obviously, the increase in funding and the concern of governments to improve the impact of science has brought deep changes and the situation is no longer as it used to be. Authorities and senior researchers occupying management positions must be concerned with producing changes that are necessary to help young scientists to achieve their desires; since it is clear that they are currently facing a tougher, more competitive and more rigorous academic environment than in the past. This scenario does not much change when finally a young researcher reaches a position and becomes a young professor or researcher. At this moment, after the initial euphoria, the requirements change: teaching, setting up a laboratory, entering the graduate system and publishing; in other words, they have to get funding and to produce outstanding papers besides developing their undergraduate assignments. For all this, young professors/researchers do not have enough support from Institutions that do not care about improving their leadership skills and supporting them to write excellent research projects to obtain funding for their laboratories. Fostering the improvement of skills to become a highly competitive and successful professor/researcher is a concern of many scientific societies and NGOs that contribute with leadership and project/papers writing courses.

The idea of this special issue has flourished with the intention of offering the opportunity to disseminate their science in an international vehicle of the Brazilian Chemical Society. The Brazilian chemistry community should be proud of the excellent and select population of young talents that already stand out in the national and international scenario.

Roberto M. Torresi

JBCS Editor

IQ-USP 